\title{
The UnMOOCing Process: Extending the Impact of MOOC Educational Resources as OERs
}

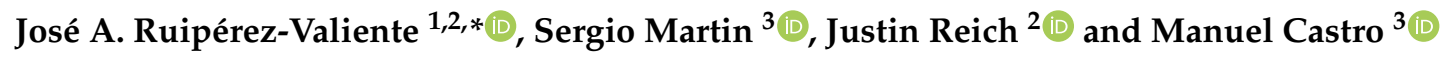 \\ 1 Department of Information and Communication Engineering, University of Murcia (UMU), \\ 30008 Murcia, Spain \\ 2 Teaching Systems Lab, Massachusetts Institute of Technology (MIT), Cambridge, MA 02139, USA; \\ jreich@mit.edu \\ 3 Department of Electrical and Computer Engineering, Universidad Nacional de Educación a Distancia \\ (UNED), 28040 Madrid, Spain; smartin@ieec.uned.es (S.M.); mcastro@ieec.uned.es (M.C.) \\ * Correspondence: jruiperez@um.es; Tel.: +34-868-887-865
}

Received: 21 July 2020; Accepted: 3 September 2020; Published: 8 September 2020

\begin{abstract}
Massive Open Online Courses (MOOCs) came into the educational ecosystem attracting the attention of the public media, businesses, teachers, and learners from all over the world. The original courses were completely open and free, targeting the worldwide population. However, current MOOC providers have pivoted towards more private directions, and we often find that MOOC materials are completely closed within their hosting platforms and cannot be retrieved from them by their learners. This diminishes the potential of MOOCs by making content available to a small proportion of learners and severely limits the reusability of the educational resources. In this paper, we present a process that we call 'unMOOCing', in which we transform the resources of a MOOC into OERs. We taught a MOOC on Open Education in the UNED Abierta platform, and we 'unMOOCed' all of its educational resources, making them available to download by the learners that are taking the course. The results of the unMOOCing were very encouraging: the possibility of downloading the course resources was the most highly rated component of the course. Additionally, the two unMOOCed materials that were considered as most useful (presentations and contents in a PDF) were downloaded by $90 \%$ of the learners. Now that the majority of MOOC providers are moving towards a more closed educational approach, we believe that this paper sends a powerful message for bringing back the original MOOC concept of 'Openness' with the unMOOCing process, thus contributing to the wider dissemination and democratization of education across the globe.
\end{abstract}

Keywords: open educational resources; unMOOCing; open education; massive open online courses; learning analytics; technology-enhanced learning; open courseWare

\section{Introduction}

It was 2012 when the New York Times decided to name the year as "The Year of the MOOC" [1], attracting the attention of the public media, businesses, teachers, and learners from all over the world. Massive Open Online Courses (MOOCs) were perceived as a very powerful tool to improve the experience of learners in distance education, while expanding the number of learners that could access higher education [2]. Researchers were extremely excited to study large numbers of learners from the entire world at the same time [3], educators were equally excited with the challenge of teaching at scale [4], and companies also perceived the entrance of MOOCs in higher education as an opportunity for new business models [5]. Moreover, a literature review on educational research in e-learning from 2009 to 2018 categorized MOOCs as the most researched e-learning modality [6]. MOOCs are being used to educate learners at scale across numerous topics [7]. 
Beyond all this hype, there were also numerous challenges for a sustainable future of MOOCs [8]. Perhaps the most closely related to our work was regarding the future directions and financial sustainability of MOOCs. These courses were completely free at the beginning and were bootstrapped by investments of venture capital [9]; however, their future role in the higher education ecosystem remained unclear. Universities invested important efforts to prepare production pipelines, build new multimedia departments, acquire equipment, retrain their professors to teach MOOCs, and so on [10]. A natural transition that happened was to reuse these contents in Small Private Online Courses (SPOCs) [11] and also the emergence of Massive Private Online Courses (MPOCs) [12], which is a new modality that is becoming increasingly important for professional training and in partnership with universities [13]. However, our line of work is not aligned with these private directions.

Our motivation lies on the original 'Open' nature of MOOCs. The term 'Open' has been a controversial one and there have been multiple views [14]; in this work, we understand Open as no fees or requirements to sign up to a course. Based on this premise, it makes total sense that their materials would follow traditional Open Educational Resource (OER) ideas, and should be completely available to be reused by other educators and learners. However, this has not been the case, and MOOC materials are often closed within their hosting platforms and cannot be retrieved from them by their learners. Therefore, some colleagues have argued that MOOCs should enhance their open educational practices [15].

Previous work presented the idea that a MOOC could be built based on OERs [16]; in this study, we follow the opposite direction by transforming the MOOC materials into OERs and we call this process 'unMOOCing'. In this work, we take a MOOC on Open Education that has been taught by the coauthors of this manuscript and others, and we unMOOCed all of its educational resources, making them available to download by the learners that are taking the course. The clear motivation is to transform these MOOC resources into OERs for learners to take with them to teach new courses or reuse the content in the future as desired. More specifically, we have the following objectives:

1. Present the unMOOCing concept and apply these ideas in a MOOC on Open Education.

2. Analyze the background and interests of learners that enroll in an Open Education MOOC and its educational resources.

3. Evaluate the MOOC and the preferred types and formats of educational resources that learners would like to download from a MOOC.

The reminder of the manuscript is organized as follows. Section 2 presents a review of related work regarding the evolution of Open Education and its connection with MOOCs; while in Section 3, we present in detail the unMOOCing concept. Section 4 describes the methodology that we have conducted in our case study and Section 5 analyze its results. We finalize the paper with a discussion and implications for practice in Section 6, and conclusions and future work in Section 7.

\section{Related Work}

Open Education is a way of producing, sharing, and building on knowledge. It seeks to remove unnecessary barriers to the learning process [17]. Open Education has been gathering a growing notoriety among academics and practitioners during last years, as its scientific impact in a number of publications can prove [18], even in STEM fields [19].

This is a term involving many topics that have been evolving among time. The first known exponent of this Open Education culture was OpenCourseWare (OCW). The OCW movement became publicly known thanks to the MIT OpenCourseWare in 2002. The movement was an international success thanks to its replication in many other institutions around the globe delivering many digital courses openly on the Web [20]. The main principles of this initiative were that OCW:

- Is a free and open digital publication of high-quality educational materials, organized as courses.

- Is available for use and adaptation under an open license, such as certain Creative

Commons licenses. 
- Does not typically provide certification or access to faculty.

During 2001, the term "learning object" gained momentum [21], and later on, more emphasis started to be made on the reusability of these learning objects [22,23], so that the concept of building up courses based on these objects could scale up. Learning objects were perceived as a potential new agent of change that could disrupt the current educational paradigm [24]. Later on, and building up on these previous learning objects, the term OER was coined during an OCW forum [25]. The OER concept refers to any digital educational resource openly available for teachers and students for consultation, use, and adaptation for noncommercial purposes.

The next evolution of the Open Education movement was towards MOOCs. The MOOC concept started in 2008, when George Siemens and Stephen Downes created what we may call the first MOOC: "Connectivism and Connective Knowledge" [26]. These MOOCs were defined as cMOOCs, and they were about connecting people and sharing participant ideas [27]. The MOOCs that came later were more focused on content delivery at scale and were known as xMOOCs [28]. There have been attempts to classify MOOCs in different ways [29], but in this work, we focus on the MOOC concept broadly and not in any specific category.

MOOCs have proven to be an effective tool in some aspects of online Open Education. However, they still have problems such as high dropout rates, low student motivation, and low interest in the provided certification by the labor market. For those reasons, researchers have created many kinds of MOOCs and with different purposes to try to solve these problems [30].

Other common problem when designing MOOCs related to practical topics is how to address the practice activities [31]. This is very common with engineering MOOCs. Distance and online education has solved this problem by implementing virtual and remote labs into the virtual courses [32]. However, the massive component of MOOCs makes it very complicated to use remote laboratories because they usually have some kind of access limitation.

On the other side, MOOC maintenance and sustainability is also an important challenge. Many institutions are struggling with how to extend the life of MOOCs to make them self-paced through, for example, redesigning the MOOC activities to avoid teacher or facilitator interaction. This redesign may include replacing collaborative activities by multiple-choice questions with automated feedback [33].

One other rising issue around MOOCs is that more and more features are not free anymore. Everything was free and open in the first MOOCs, from videos to certificates. Then, certificates became one of the first ways of monetizing MOOCs. However, students could still watch the videos for free. Later, many MOOCs also moved more features of the learning experience behind a paywall, for example, graded assignments. Currently, most of the MOOC providers have some completely paid courses [34]. Moreover, in the majority of MOOCs, once the course is over the contents are no longer available to the learner.

MOOCs have been considered part of the Open Education movement mainly because of their open enrollment feature, but in most cases, they are no longer open in the sense of allowing reusing and repurposing their contents. Huttner-Loan et al. [35] delivered a MOOC under a Creative Commons licence, but they did not provide an easy way for the students to download and reuse the course contents.

For that reason, the present research study introduces a MOOC where all its resources (video-lectures, contents, assessments, and PowerPoint presentations) have been converted into OERs to augment the open feature of MOOCs and facilitate the reusability of the contents.

\section{The unMOOCing Process}

The original connectivist MOOCs were 'open' in at least three ways [36]. They had open enrollment in the sense that anyone could participate without cost or prerequisite. They were openly licensed, in the sense that content was often released under a Creative Commons or similar "some 
rights reserved" license and software was open source. They took place on the open web rather than behind logins or paywalls.

The turn to xMOOC platforms has made these commitments more difficult to maintain. While many courses still have no prerequisites, increasingly there are paywalls limiting access to some content, most MOOC platforms are not open source (Open edX stands out as a noteworthy exception), most MOOC content is not openly licensed, and most of that content is hard coded into platforms that are walled off from the open Web by logins.

While this shift away from principles of openness is lamentable, MOOC platforms do have some affordances: they support a linear, instructor-paced learning experience and some MOOC providers have some proficiency with marketing and learner recruitment. One way to take advantage of the benefits of MOOC platforms while also aspiring to principles of openness is through "unMOOCing" - making MOOC content available through more accessible forms on the open Web. UnMOOCing is the process of taking openly licensed content originally designed for an instructor-paced MOOC and releasing it through one or more venues on the open Web so that the learning resources can be reused and remixed by multiple audiences for multiple purposes. We have denominated this process as unMOOCing since the concept is similar to "unpacking" the contents of a MOOC. In this case, we unpack the contents of a MOOC in a number of OERs, and we informally call these resources as unMOOCed materials, since now they are not part of a MOOC but OERs instead.

The starting point for unMOOCing is assuring that, to the maximum extent possible, MOOC content is released under an open license that allows participants to remix and reuse course content. This involves thinking through the development of all content resources-text, images, audio, video, and software-to ensure that course developers have the appropriate rights to openly license their materials [35]. If the original MOOC learning resources are openly licensed, then all of those materials can be in a variety of forms on a variety of platforms. Course videos can be uploaded as playlists on YouTube or Vimeo. Course texts and links can be reposted as a "course-to-go" in a PDF or through a Google Doc. Audio resources can be released as podcasts. The entire course can be republished as OpenCourseWare through platforms like the MIT Open Learning Library.

Through the unMOOCing process, course developers can find new audiences for their learning resources. Republishing content in new formats facilitates reuse by other educators and assures that course content remains accessible even after a MOOC finishes. Over the last decade, MOOCs have steadily moved away from some of the principles of openness that marked the early rhetoric of xMOOC entrepreneurs, and unMOOCing offers a hedge against the consistent incursion of paywalls and other content limitations.

\section{Methods}

This section provides as part of Section 4.1 an overview of the MOOC, where we implemented the unMOOCing case study; then, in Section 4.2, we describe the study and instrument design; and finally, in Section 4.3, we provide a brief description of the data collected.

\subsection{Overview of Foundations to Open Education and OERs Repositories}

Open education and OERs are deeply influencing and transforming the educational environment. The "Foundations to Open Education and OERs repositories" MOOC offers a practitioner's view of Open Education, OERs, Open Education science, repositories, and applications for educators and professionals. This 6-module course is designed to provide a comprehensive understanding of the ways in which Open Education and open educational resources are changing the rules of education. It was delivered from March to June 2020 through an Open edX instance deployed at the Universidad Nacional de Educación a Distancia (UNED) of Spain.

The purpose of the course is to help faculty and professionals dedicated to education to understand the advantages of Open Education and how they can apply it to their everyday teaching. As a main innovation in this course, authors provide a final unit where participants can find all the didactic 
resources developed or gathered to prepare the MOOC. The aim is to provide the unMOOCed resources to facilitate participants the reuse of all resources as OERs for their own purposes.

On completing this course, students strengthened their knowledge and career potential by demonstrating an understanding of the different units that are depicted in Table 1. Additionally, Table 1 also presents a detailed description of the structure and the contents developed as part of the course. The resources developed for the course include intro videos, video-lectures (e.g., Figure 1a), and video conclusions as additional resources. The course also includes mandatory and additional readings, basically consisting of links to websites and digital resources where students can learn the details of the content explained in the video lectures. Finally, each module includes several research exercises where the students must research about a certain topic on the Internet, perform an activity, and discuss it in the forum with their peers (e.g., Figure 1b).

Table 1. Overview of the contents in each unit of the course. OER-Open Educational Resource, MOOC-Massive Open Online Course.

\begin{tabular}{|c|c|c|c|c|c|c|}
\hline Unit & Questionnaires & Videos & $\begin{array}{l}\text { Mandatory } \\
\text { Reading }\end{array}$ & $\begin{array}{l}\text { Additional } \\
\text { Resources }\end{array}$ & $\begin{array}{l}\text { Research } \\
\text { Exercises }\end{array}$ & $\begin{array}{c}\text { Forum } \\
\text { Threads }\end{array}$ \\
\hline 0: Start of the course & Presurvey & 2 & $x$ & $x$ & $x$ & $x$ \\
\hline $\begin{array}{l}\text { 1: Introduction to Open } \\
\text { Education \& OERs }\end{array}$ & $\begin{array}{l}\text { Pre- and } \\
\text { post-test }\end{array}$ & 6 & 8 & 4 & 4 & 4 \\
\hline 2: Repositories & $\begin{array}{l}\text { Pre- and } \\
\text { post-test }\end{array}$ & 6 & 2 & 10 & 1 & 1 \\
\hline $\begin{array}{l}\text { 3: Applications to Academic } \\
\text { and Industry }\end{array}$ & $\begin{array}{l}\text { Pre- and } \\
\text { post-test }\end{array}$ & 7 & 6 & 30 & 4 & 4 \\
\hline 4: Applications for OERs & $\begin{array}{l}\text { Pre- and } \\
\text { post-test }\end{array}$ & 6 & 2 & 33 & 3 & 4 \\
\hline $\begin{array}{l}\text { 5: Open Science } \\
\text { Education }\end{array}$ & $\begin{array}{l}\text { Pre- and } \\
\text { post-test }\end{array}$ & 6 & 7 & 52 & 4 & 4 \\
\hline 6: End of the Course & Postsurvey & $x$ & $x$ & unMOOCing & $x$ & $x$ \\
\hline
\end{tabular}

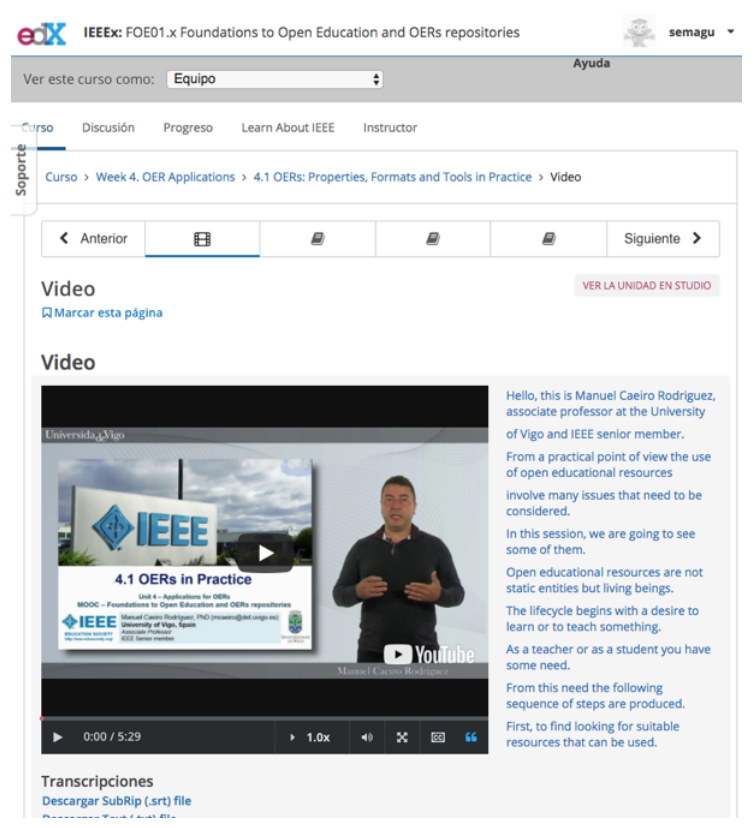

(a)

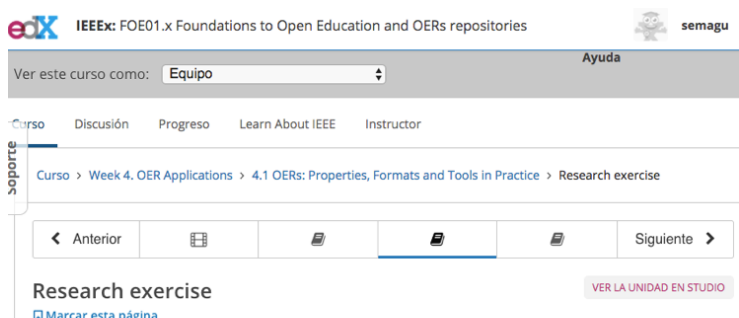

ఐMarcar esta página

Research on the Internet about open formats and open source tools for 3 different types of resources that you may be interested in. You can also propose some proprietary format or tool if you think they can be encourage you to publish your findings in the following thread of the forum and provide opinion about yours and other students' findings.

(b)

Figure 1. Two screenshots of the virtual course. (a) Example of video lecture; (b) Example of research exercise. 


\subsection{Study and Instrument Design}

First, we present an overall schema of the four stages in the study:

1. Students perform a presurvey that they are required to complete before accessing the rest of the course contents.

2. Students interact with the course materials normally. The course was open from 26th March to 9th July of 2020.

3. Once students complete the course, the last unit has, as special content, the unMOOCed materials in the form of links that students are encouraged to download.

4. Students perform a postsurvey once they have finished with the course materials. Students are encouraged to complete it by providing a bonus grade if they do so.

\subsubsection{Presurvey}

The instrument design of both the pre- and postsurvey is based on previous instruments applied to large scale surveys from MITx and HarvardX [37]. The presurvey is built in order to better understand the background and interests of learners. The full survey is available in Appendix A.1, and the main points that the presurvey aims to measure are as follows:

- Intentions and reasons to take the course.

- Interest in Open Education and in downloading the course contents.

- Students' demographics and background.

\subsubsection{Course Interaction}

In the second stage, students interact with the course normally. The course is dense, with numerous readings, videos, research exercises, forum threads, and additional resources as can be seen in Table 1.

\subsubsection{The unMOOCing Implementation}

Once they finish their interaction with the course, in the last unit, students are able to access the unMOOCed educational resources. We have implemented the unMOOCing in this case study by making available the following MOOC contents via direct links:

- SlideShare links with all the presentations in the course and a single ZIP file with all PowerPoint presentations.

- YouTube channel with playlists for each one of the units of the course (note there are numerous online and free tools that allow you to download YouTube videos to your local machine).

- Word file with the questionnaires for all modules (this includes pre- and post-tests, i.e., the assessment of the course).

- Word file with all the additional references of mandatory readings, additional materials, and research exercises of each module.

We sent several reminders to students indicating that the unMOOCed materials were available to maximize students' awareness regarding the unMOOCing process.

\subsubsection{Postsurvey}

Finally, once students finish the course contents and review the unMOOCing section, they have access to the post-course survey of the course. This survey is created with the objective of evaluating the course and the unMOOCing process in order to improve it in the future and to offer guidelines. The full survey is available in Appendix A.2 and the main points that the post-survey aims to measure are as follows: 
- Evaluation of the course design and materials.

- Evaluate the usefulness of the unMOOCed materials.

- Analyze the plans that students have with those materials.

- Obtain feedback regarding which other MOOC materials could be useful.

\subsection{Data Collection}

We collected data from a single course iteration that was available from the 26th March to 9 th July of 2020. We combined data from three different sources. First, we examined the clickstream data obtained from the Open edX platform, which we used to generate information regarding grading. Then, we also used the precourse survey responses and the post-course survey responses. These three sources were merged into a single dataset to perform a combined analysis.

A total of 440 students registered for the course, however, only 82 of them obtained a grade above 0 . We received 200 precourse survey responses and 89 post-course survey responses.

\section{Results}

The results are distributed in two parts: Section 5.1 presents results regarding the background and interests of learners that are interested in Open Education (our second research objective). Then, Section 5.2 presents the evaluation of the course and the unMOOCed resources (our third research objective).

\subsection{Background and Interests of Learners That Enrolled in the MOOC}

This subsection reviews the demographics and background of the learners that enrolled to the course. This is particularly informative to understand what kind of learners were interested in the course, and their potential interest in downloading the unMOOCed resources. As a reminder, you can read the full questions of the presurvey in the Appendix A.1.

First, in Figure 2, we show the distribution of gender (left), a histogram with the age distribution (middle), and the distribution by level of education (right). We can see that the gender distribution is fairly equitable, with approximately a $50 \%$ of each gender. In terms of age, the distribution seems fairly normal, and the blue line represents the mean age of the learners, which is 41.4 years old. Finally, we can also see how the population of learners is highly educated, with more than $90 \%$ of them having a Doctorate or Master degree.

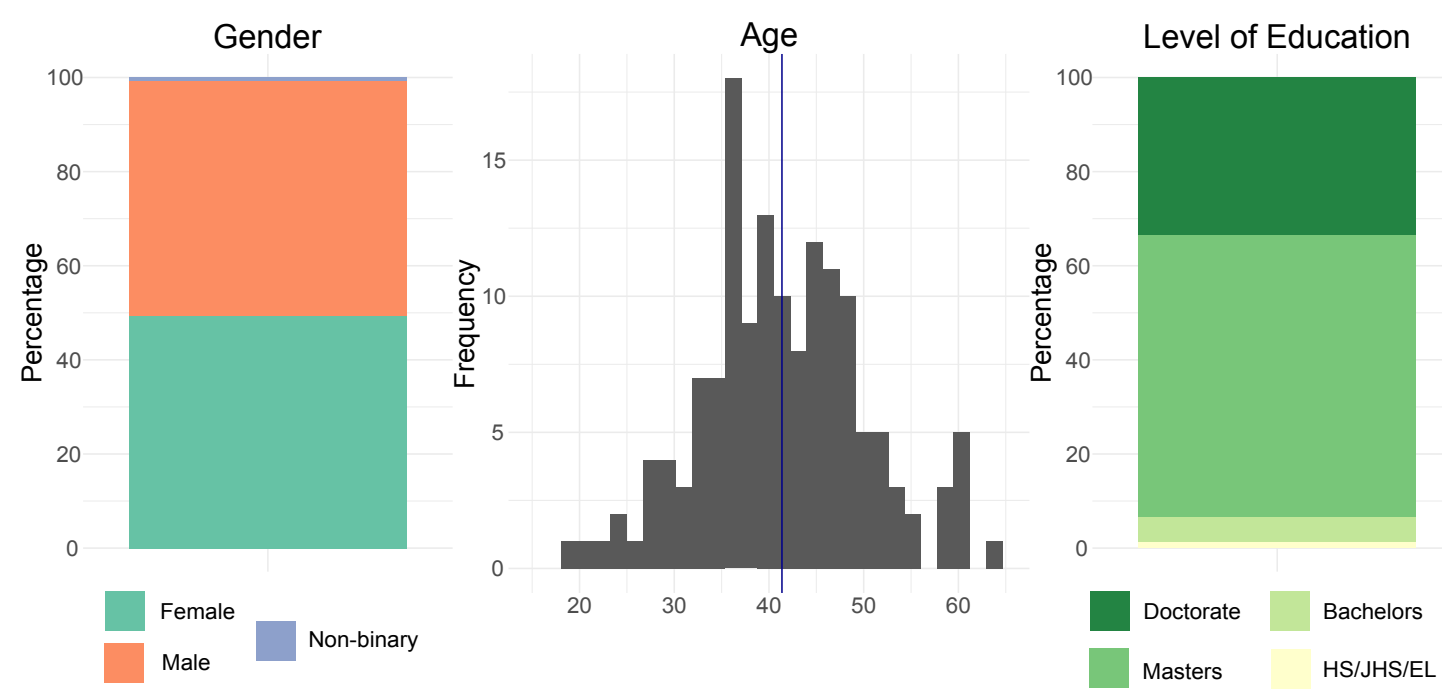

Figure 2. Distribution of gender, age, and level of education of learners based on precourse survey. 
Second, in terms of the background and previous experience of learners, Figure 3 shows their background as educators (left), their previous experience with Open Education (middle), and their reasons to enroll in the course (right). The majority of the learners (85\%) are already educators, but only $30 \%$ of them have taught or will teach a course on Open Education. However, $90 \%$ of them would be interested in downloading the course contents if these were available. In general, learners are not specially familiar with Open Education, as only $20 \%$ of them reported to be extremely or very familiar with Open Education. Finally, the main reasons to enroll in the course are to advance their career or their education with $90 \%$ of the learners reporting that those reasons apply to them, and $60 \%$ of the learners also report interest in improving their English levels through the course.
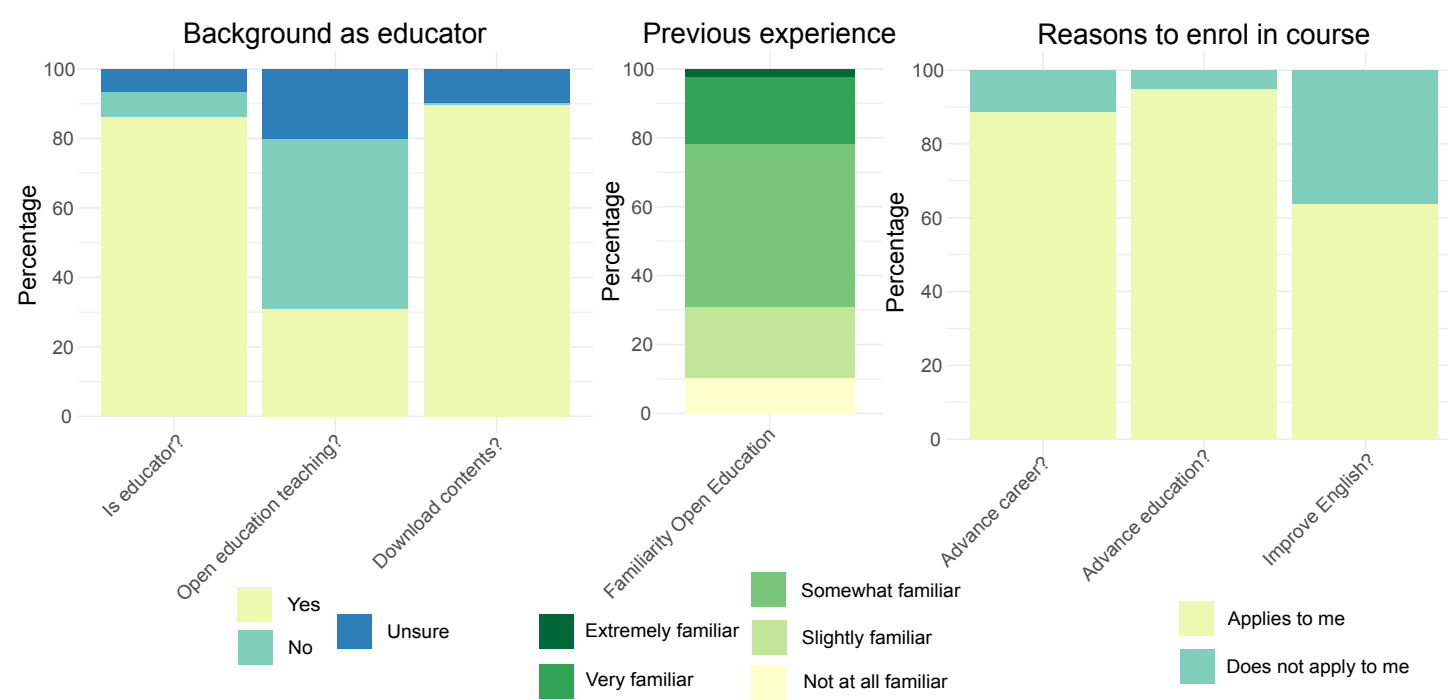

Figure 3. Distribution of the background and previous experience of learners as well as their reasons to enroll in the course based on precourse survey.

\subsection{Evaluation of the Course and the unMOOCed Resources}

This subsection presents results regarding the course evaluation and the unMOOCed resources, which can provide critical feedback for future Open Education courses and the implementation of the unMOOCing process. As a reminder, you can read the full questions of the postsurvey in the Appendix A.2.

First, Figure 4 presents the learning and difficulty experienced (left) and the course rating by each component (right). The results indicate that $90 \%$ of the learners learned a great deal or a fair amount, while none of the learners reported having learned little or nothing. Additionally, $60 \%$ of the learners reported that the course was appropriately challenging, and all learners except one reported that the course was either difficult, appropriately challenging, or easy. Only one learner rated the course as too difficult and none of them as too easy. Therefore, we consider that the difficulty was appropriate. Finally, in terms of course ratings, most of the components were evaluated with $80 \%$ of the students considering the component as excellent or very good. The discussion forums were the worst rated component, and the possibility to download the contents as unMOOCed resources was the one that received the highest rating. 

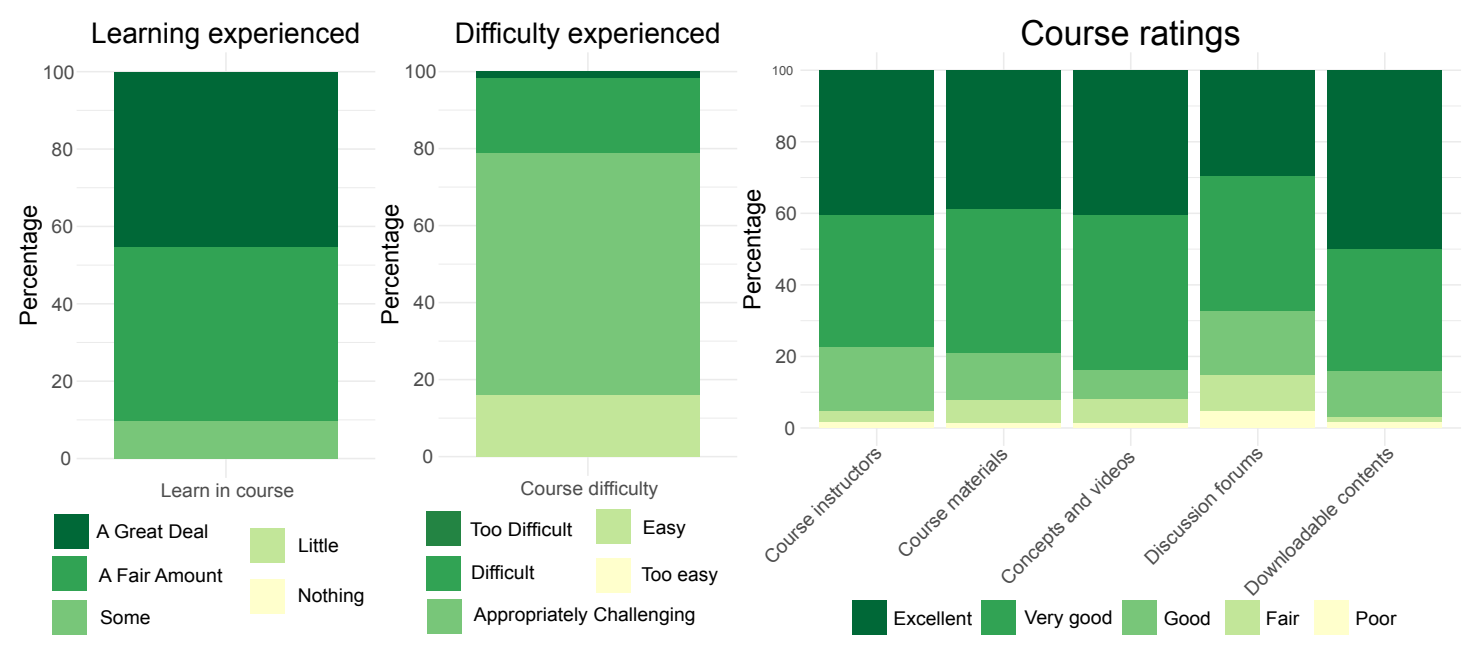

Figure 4. Course evaluation based on experienced learning and difficulty, and course rating of different components based on postcourse survey.

Second, in Figure 5, we have the usefulness rating for each type of unMOOCed resource (left) and also those unMOOCed resources that learners reported as downloaded or that they planned to download. In terms of the usefulness, it is important to remind that the first four unMOOCed resources (i.e., presentations, videos, content, and assessments) were the ones that we provided as unMOOCed resources in this course, and that the four last unMOOCed resources (raw figures, recommended readings, entire course link, or a permanent course site similar to OpenCourseWare) were other resources that were rated for potentially being incorporated as future work. All of the contents were highly rated, with all of them being considered as extremely or very useful by $80 \%$ of the learners except for the raw figures. The most highly rated unMOOCed resources were the presentations and the contents as PDF, where $95 \%$ of learners rated them as extremely or very useful. This is connected to the fact that those were also the two most downloaded materials, with $90 \%$ and $85 \%$ of learners respectively reporting that they had downloaded (or planned to) those two unMOOCed resources. More in general, $70 \%$ of the learners indicated that they had downloaded (or planned to) all of the unMOOCed resources including the presentations, videos, contents, and assessments as PDF.
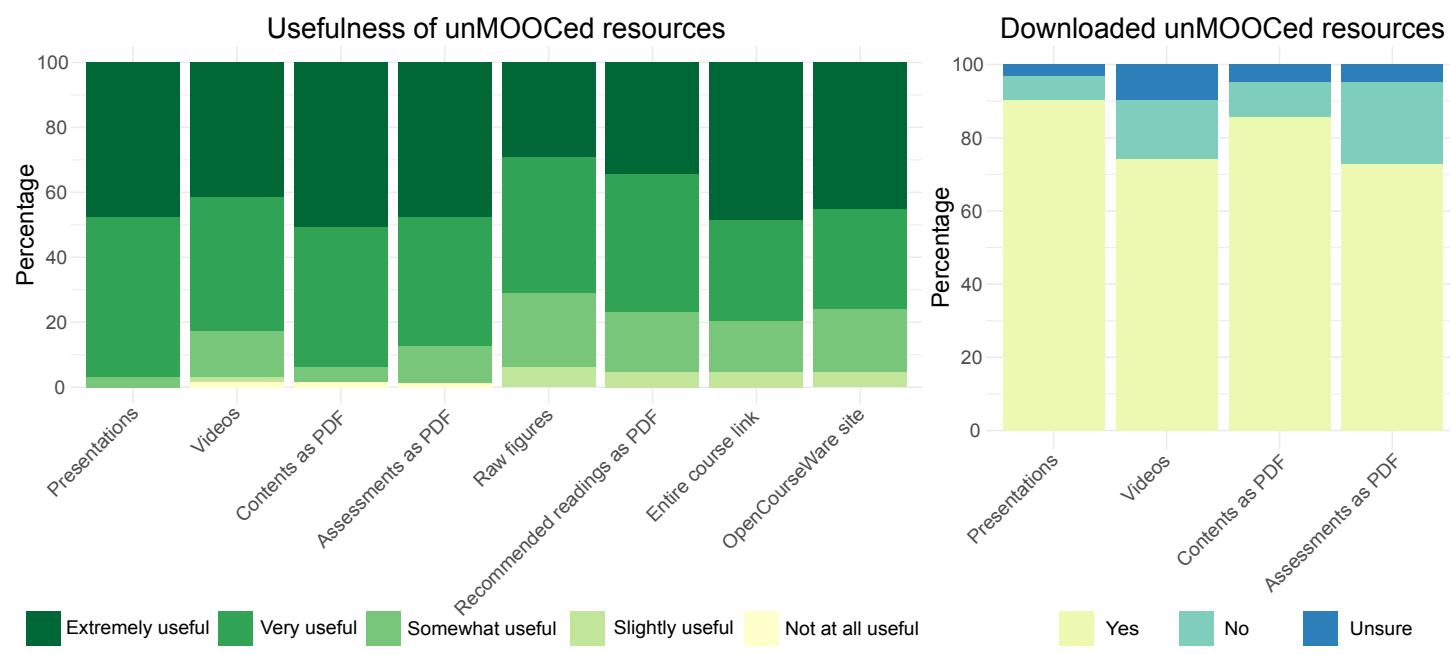

Figure 5. Usefulness of each of the proposed unMOOCed resources and which of the ones available students downloaded (or plans to) based on postcourse survey. 


\section{Discussion}

The majority of the learners were around 40 years old, had a Doctorate or Master's degree, were educators with not much experience with Open Education, and were interested in advancing their career and education. The main difference with the typical MOOC demographics reported in the literature is in the level of education, since in this case study, $30 \%$ and $60 \%$ of the learners reported having a Doctorate or Master's degree respectively, and thus $90 \%$ of the learners had one of these two degrees. However, in the literature we find that in the majority of MOOC providers, the percentage of learners with a Doctorate is usually below $10 \%$, and the percentage of learners with either a Doctorate or Master's degree is around 30-60\% [38]. Since there are numerous educators and the UNED Abierta platform is supported by a university, we think that there might be a high number of university professors and graduate students taking the course, which can explain this high proportion of learners with advanced degrees. Across the MITx and HarvardX MOOC portfolio, 32\% of the learners reported being educators [37], and thus, this much larger presentation of $85 \%$ of educators in our case is most probably related to the topic of the course.

One key highlight is that in the presurvey responses, $90 \%$ of learners reported that they would be interested in downloading the course contents before the MOOC started; and then as part of the postcourse survey, the two most downloaded unMOOCed resources (presentations and contents as PDF) had a percentage of downloads of around $90 \%$. Therefore, we see that the intentions before the course and actions by the end of the course connect together nicely, and learners were able to fulfill their wish to obtain the course resources. The other two unMOOCed (videos and assessments as PDF) resources were also downloaded widely, with students reporting around $70 \%$ of downloads.

The two most downloaded resources were also the most highly rated in terms of usefulness, but most of the learners regarded most of the potential unMOOCed resources as extremely or very useful. For example, learners also rated highly ( $80 \%$ them as extremely or very useful) a quick option to download all resources, either with a single link or via a platform that can host the course permanently, such as an OpenCourseWare site. While in the literature it was argued that during the evolution, OpenCourseWare sites could be transformed into MOOCs [39,40], we could also see the opposite direction in which current MOOCs can also be moved into an OpenCourseWare site. It would also be viable to have the two course formats coexisting at the same time to augment the impact of producing the educational resources; in this potential scenario, separating the Course Management System (CMS) (OpenCourseWare or similar sites) from the Learning Management System (LMS, the MOOC provider) could be helpful. In the case of Open edX, one could imagine that in the same way that a course author can publish the course to the LMS, it would also be possible to publish it into a different site where the resources are available permanently and downloadable by students or interested stakeholders. A similar initiative is being developed by the MIT Open Learning Library site, where they host some of their courses from MIT OpenCourseWare and MITx with materials that are free to use.

More work would be needed to guarantee a seamless integration between these courses, and the use of Linked Open Data (LOD) shows high promise [16]. We are not the first ones to indicate that LOD could play an important role in MOOCs. Previous authors presented the vision of LOOCs (Linked Open Online Courses) to avoid the monolithic and closed creations [41], other colleagues proposed MOOCLink that seeks to integrate data from different MOOC providers [42], and previous work also used LOD to automatically matching MOOC learning outcomes with learners' needs [43]. Thinking about potential platforms that could host the unMOOCed resources, the use of LOD could play an important role; for example, by greatly facilitating the findability, reusability, and interoperability of these materials.

In terms of the course evaluation, most learners reported having experienced a great deal or fair amount of learning, and that the course was appropriately challenging. Additionally, the course ratings were excellent or very good in general. The lowest rating went to the discussion forums, and this might have been caused by the fact that we did not count with the help of a teaching assistant that could provide timely support in the forums. The better rated component was the possibility of 
downloading the unMOOCed resources, and thus, this reinforces our idea and the potential impact of the unMOOCing process. Therefore, we consider a high success for both the course and the unMOOCing initiative. The main limitation of our conclusions is related to the generalization of our results. First, because we have experimented with a single course; and second, because the majority of our learners are educators and that can have an impact on their interest in downloading the unMOOCed resources.

We believe that our results represent preliminary insights that MOOC learners are interested in downloading the contents of the courses they take, and that if the resources are unMOOCed, a large proportion of them might do so. These results send a message to MOOC practitioners and administrators to transform their frequently closed MOOC resources in OERs that learners can access openly to teach new courses or reuse the content in the future as appropriate, consequently augmenting the impact of these courses exponentially.

\section{Conclusions and Future Work}

In this paper we have presented the process that we call unMOOCing, in which we transform the resources of a MOOC into OERs. We took the contents of an Open Education MOOC, and we unMOOCed all of its educational resources making them available to download by the learners that are taking the course. The results of the unMOOCing were very encouraging, the possibility of downloading the course resources was the most highly rated component of the course. Additionally, the unMOOCed materials that were considered as most useful-the presentations and contents in a PDF-were downloaded by $90 \%$ of the learners. While the generalization is limited, these results exemplify the potential impact that the unMOOCing process could have if implemented systematically across an entire MOOC provider.

In this case study, we made the materials available at the end of the course, but another possibility would be to make them available at the beginning of the course. This could help learners to decide if they should stick to the course schedule or download the materials for later. Eventually, the objective of the unMOOCing process would be to systematically have MOOC materials easily available to the learners and other unregistered people. Since we do not want to increase the workload of the course staff with an additional burden, this process should be transparent and seamless for the course staff. Therefore, new features and infrastructure would be required to guarantee an easy workflow, with the final objective of making the unMOOCing process systematically available at an institution or MOOC platform level. This thinking might be against some corporate MOOC companies since it could mean to 'lose clients', therefore, it seems like support from the institutions (universities or others) might be a more promising direction.

Future studies should aim to apply the unMOOCing process to other MOOCs and analyze if the results in terms of ratings and downloads generalize from this study. Additionally, future studies should plan to conduct a follow-up study in a second phase-for example, half a year later, where they can ask learners that downloaded the unMOOCed resources how those materials were eventually used. This can help to better estimate the real impact of the unMOOCing process.

Now that the majority of MOOC providers are moving towards a more closed educational approach, we believe that this paper sends a powerful message for bringing back the original MOOC concept of 'Openness' with the unMOOCing process, thus contributing to the wider dissemination and democratization of education across the globe.

Author Contributions: Conceptualization, J.A.R.-V., S.M. and J.R.; data curation, J.A.R.-V.; formal analysis, J.A.R.-V.; funding acquisition, M.C.; methodology, J.A.R.-V. and S.M.; project administration, S.M.; resources, M.C.; visualization, J.A.R.-V.; writing-original draft, J.A.R.-V., S.M. and J.R.; writing—review \& editing, J.A.R.-V., S.M., J.R. and M.C. All authors have read and agreed to the published version of the manuscript.

Funding: This work has been co-funded by the Madrid Regional Government, through the project e-Madrid-CM (S2018/TCS-4307). The e-Madrid-CM project is also co-financed by the Structural Funds (FSE and FEDER). We would like to acknowledge support from the MIT-SPAIN "la Caixa" Foundation SEED FUND, the Spanish 
Ministry of Economy and Competitiveness through the Juan de la Cierva Formación program (FJCI-2017-34926) and the Industrial Engineering School of UNED and their projects 2020-IEQ13 and 2020-IEQ14.

Acknowledgments: The authors acknowledge the IEEE Education Society for supporting the project "Development of first MOOC of the Education Society in the Open Education and OER field." We also want to thank the rest of the teaching team: Manuel Caeiro and Martín Llamas from Vigo University, Gabriel Díaz and Beatriz Martín from UNED, Óscar Martínez Bonastre from Miguel Hernández University of Elche, Rebecca Strachan from Northumbria University, and Edmundo Tovar from the Technical University of Madrid.

Conflicts of Interest: The authors declare no conflict of interest.

\section{Appendix A. Questionnaires}

\section{Appendix A.1. Precourse Survey}

For us to offer the best course experience possible, we would like to ask you to answer a few questions about yourself. Whether you are just browsing or you are determined to complete the entire course, the more we know about you, the better we can serve all students in this course. As one of the first students in this new, free offering, your responses will be especially important to us.

There are no right or wrong answers or responses, and your honest feedback is very important to us. For more information about how we use and protect this data, please refer to the UNED Abierta terms of service. Thank you for taking this survey.

1. Which statement best describes your plan for taking this course?

- I plan to take this course from start to finish

- I plan to take some parts of this course

- I plan to just browse this course

- I am not sure yet

2. How many course assessments (quizzes, tests, etc.) do you intend to complete?

- All assessments

- Most assessments

- A few assessments

- No assessments

3. Why did you enroll in this course? [Applies to me/Does not apply to me]

- To advance my career

- To advance my education

- For enjoyment

- To improve my English skills

4. How familiar are you with the topics in this course?

- Extremely familiar

- Very familiar

- Somewhat familiar

- Slightly familiar

- Not at all familiar

5. How important is learning the Open Education materials in the course to you?

- Extremely important

- Very important

- Moderately important 
- A little important

- Not at all important

6. Are you currently (or in the future) teaching a class related to the topic of this course?

- Yes

- No

- Unsure

7. Would you like to download the educational resources of the course after you finish it?

- Yes

- No

- Unsure

8. What is your goal in taking this course?

- Open text response

9. What is your gender?

- Female

- Male

- Non-binary

10. What is your year of birth? (e.g., 1985)

- Open text box

11. What is your current employment status?

- Employed

- Unemployed

- Full-time student

- Retired

- Other

12. What is the highest level of education you have completed?

- Doctorate/Ph.D.

- Masters

- Bachelors

- Secondary/High School, Middle school/Jr. High or Elementary

- Other

- None

13. How would you describe your English language skills?

- Fluent

- Proficient

- Intermediate

- Basic

- Weak 
Appendix A.2. Postcourse Survey

Thank you for participating in Foundations to Open Education and OERs repositories. For us to better understand the overall course experience, we would like to ask you a few questions about your own experience. Whether you simply browsed or completed the entire course, the more we know about you, the better we can serve students in future courses.

There are no right or wrong answers, and your honest feedback is very important to us. For more information about how we use and protect this data, please refer to the UNED Abierta terms of service. Thank you for taking this survey.

1. With consideration of your goals for enrolling, did this course meet your expectations?

- Far exceeded expectations

- Exceeded expectations

- Equaled expectations

- Short of expectations

- Far short of expectations

2. How much did you learn in this course?

- A Great Deal

- A Fair Amount

- Some

- Little

- Nothing

3. How would you characterize the level of difficulty of this course?

- Too Difficult

- Difficult

- Appropriately Challenging

- Easy

- $\quad$ Too Easy

4. How would you rate the below based on your experience in the course. Use 'Excellent', 'Very good', 'Good', 'Fair', or 'Poor'.

- Course instructors

- Course materials (slides and text)

- Concepts that are introduced and explained in the course videos

- Overall experience using the discussion forum

- The possibility to download some of the course contents

5. How useful do you think it is to have the possibility to download the following resources [not at all useful, slightly useful, somewhat useful, very useful, or extremely useful]:

- Presentations and Slideshare links

- Videos in YouTube and other portals

- Word/PDF with all additional contents (readings, description of exercises and so on)

- Word/PDF with assessment for each unit

6. Which resources did you download, plan to download, or save the links for later? [Yes/No]

- Presentations and Slideshare links

- Videos in YouTube and other portals 
- Word/PDF with all additional contents (readings, description of exercises and so on)

- Word/PDF with assessment for each unit

7. What are your plans with these resources?

- Open text response

8. How useful do you think it would be to have the following extra resources [not at all useful, slightly useful, somewhat useful, very useful, or extremely useful]:

- Raw files of diagrams and images

- All recommended readings in the form of .pdf files.

- A "download entire course" link with a zip that contains all contents

- A static course with all the contents in a OpenCourseware format (e.g., Education Technology Studio at OCW MIT (https:/ / ocw.mit.edu/courses/comparative-media-studies-writing/ cms-594-education-technology-studio-spring-2019/)

9. Do you have any other suggestions regarding platforms that could be used or which other resources would be important to make available after the course is finished?

- Open text response

\section{References}

1. Pappano, L. The Year of the MOOC. N. Y. Times 2012, 2, 2012.

2. Scanlon, E.; McAndrew, P.; O'Shea, T. Designing for educational technology to enhance the experience of learners in distance education: How open educational resources, learning design and MOOCs are influencing learning. J. Interact. Media Educ. 2015, 2015. [CrossRef]

3. Breslow, L.; Pritchard, D.E.; DeBoer, J.; Stump, G.S.; Ho, A.D.; Seaton, D.T. Studying learning in the worldwide classroom research into edX's first MOOC. Res. Pract. Assess. 2013, 8, 13-25.

4. Ferguson, R.; Sharples, M. Innovative pedagogy at massive scale: Teaching and learning in MOOCs. In European Conference on Technology Enhanced Learning; Springer: Berlin/Heidelberg, Germany, 2014; pp. 98-111.

5. Kalman, Y.M. A race to the bottom: MOOCs and higher education business models. Open Learn. J. Open Distance e-Learn. 2014, 29, 5-14. [CrossRef]

6. Valverde-Berrocoso, J.; Garrido-Arroyo, M.D.C.; Burgos-Videla, C.; Morales-Cevallos, M.B. Trends in Educational Research about e-Learning: A Systematic Literature Review (2009-2018). Sustainability 2020, 12, 5153. [CrossRef]

7. Calvo, S.; Lyon, F.; Morales, A.; Wade, J. Educating at scale for sustainable development and social enterprise growth: The impact of online learning and a massive open online course (MOOC). Sustainability 2020, 12, 3247. [CrossRef]

8. Fischer, G. Beyond hype and underestimation: Identifying research challenges for the future of MOOCs. Distance Educ. 2014, 35, 149-158. [CrossRef]

9. Finkle, T.A.; Masters, E. Do MOOCs Pose a Threat to Higher Education? Res. High. Educ. J. 2014, 26, 10.

10. Hollands, F.M.; Tirthali, D. Why Do Institutions Offer MOOCs? Online Learn. 2014, 18, n3. [CrossRef]

11. Muñoz Merino, P.J.; Méndez Rodríguez, E.M.; Delgado Kloos, C.; Ruiperez Valiente, J.A. Design, implementation and evaluation of SPOCs at the Universidad Carlos III de Madrid. J. Univers. Comput. Sci. 2017, 23, 167-186.

12. Guo, W. From SPOC to MPOC-The effective practice of Peking University online teacher training. In Proceedings of the IEEE 2014 International Conference of Educational Innovation through Technology, Brisbane, Australia, 27-29 October 2014; pp. 258-264.

13. Reich, J.; Ruipérez-Valiente, J.A. The MOOC pivot. Science 2019, 363, 130-131. [CrossRef] [PubMed]

14. Stracke, C.M.; Downes, S.; Conole, G.; Burgos, D.; Nascimbeni, F. Are MOOCs open educational resources?: A literature review on history, definitions and typologies of OER and MOOCs. Open Prax. 2019, 11, 331. [CrossRef] 
15. Czerniewicz, L.; Deacon, A.; Glover, M.; Walji, S. MOOC-Making and open educational practices. J. Comput. High. Educ. 2017, 29, 81-97. [CrossRef]

16. Piedra, N.; Chicaiza, J.; López-Vargas, J.; Caro, E.T. Seeking Open Educational Resources to Compose Massive Open Online Courses in Engineering Education An Approach based on Linked Open Data. J. UCS 2015, 21, 679-711.

17. What is Open Education. Available online: https://opensource.com/resources/what-open-education (accessed on 2 June 2020).

18. Martin, S.; López-Martín, E.; Lopez-Rey, A.; Cubillo, J.; Moreno-Pulido, A.; Castro, M. Analysis of new technology trends in education: 2010-2015. IEEE Access 2018, 6, 36840-36848. [CrossRef]

19. Martin, S.; Lopez-Martin, E.; Moreno-Pulido, A.; Meier, R.; Castro, M. A Comparative Analysis of Worldwide Trends in the Use of Information and Communications Technology in Engineering Education. IEEE Access 2019, 7, 113161-113170. [CrossRef]

20. Iiyoshi, T.; Kumar, M. Opening up Education: The Collective Advancement of Education through Open Technology, Open Content, and Open Knowledge; The MIT Press: Cambridge, MA, USA, 2010.

21. Downes, S. Learning objects: Resources for distance education worldwide. Int. Rev. Res. Open Distrib. Learn. 2001, 2. [CrossRef]

22. Boyle, T. Design principles for authoring dynamic, reusable learning objects. Australas. J. Educ. Technol. 2003, 19. [CrossRef]

23. Polsani, P.R. Use and abuse of reusable learning objects. J. Digit. Inf. 2003, 3, 164.

24. Wiley, D.A. The Instructional Use of Learning Objects; Agency for Instructional Technology: Bloomington, IN, USA, 2002; Volume 1.

25. Butcher, N.; Kanwar, A.; Uvalić-Trumbić, S. A Basic Guide to Open Educational Resources (OER); Technical Report; UNESCO and Commonwealth of Learning: Vancouver, UK, 2015; Available online: http:/ / hdl.handle.net/11599/36 (accessed on 2 June 2020).

26. Siemens, G.; Downes, S. Connectivism \& Connective Knowledge; Universidad de Manitoba: Winnipeg, MB, Canada, 2008.

27. Cormier, D. Rhizo14-The MOOC that community built. Int. J. Innov. Qual. Learn. 2014, 107, $108-110$.

28. Bates, T. Comparing $x$ MOOCs and cMOOCs: Philosophy and Practice; Online Learning and Distance Education Resources: Vancouver, BC, Canada, 2014.

29. Conole, G. A new classification schema for MOOCs. Int. J. Innov. Qual. Learn. 2014, 2, 65-77.

30. Hew, K.F.; Cheung, W.S. Students 'and instructors' use of massive open online courses (MOOCs): Motivations and challenges. Educ. Res. Rev. 2014, 12, 45-58. [CrossRef]

31. Yuan, L.; Powell, S. MOOCs and disruptive innovation: Implications for higher education. eLearning Pap. 2013, 33, 1-7.

32. Loro, F.G.; Losada, P.; Gil, R.; Rey, A.L.; San Cristobal, E.; Molina, C.P.; Diaz, G.; Castro, M. Real Experiments in a MOOC Through Remote Lab VISIR: Challenges, Successes and Limits. In Proceedings of the IEEE 2018 Learning With MOOCS (LWMOOCS), Madrid, Spain, 26-28 September 2018; pp. 98-101.

33. Rodriguez, B.C.P.; Nieto, M.C.R. How to Run a Massive Open Online Course Once the Funding is Over. In European MOOCs Stakeholders Summit; Springer: Berlin/Heidelberg, Germany, 2019; pp. 156-161.

34. Shah, D. MOOCs Started Out Completely Free. Where Are They Now? 2017. Available online: https: / / www.classcentral.com/report/moocs-started-completely-free-now/ (accessed on 2 June 2020).

35. Huttner-Loan, E.; Beazley, G.; Glenwerks, C.; Napier, A.; Littenberg-Tobias, J.; Reich, J. Making a Creative Commons MOOC: Challenges and Opportunities. In Proceedings of the IEEE 2018 Learning with MOOCS (LWMOOCS), Madrid, Spain, 26-28 September 2018; pp. 81-84.

36. Ozturk, H.T. Examining value change in MOOCs in the scope of Connectivism and Open Educational Resources movement. Int. Rev. Res. Open Distrib. Learn. 2015, 16, 119-143. [CrossRef]

37. Chuang, I.; Ho, A. HarvardX and MITx: Four Years of Open Online Courses-Fall 2012-Summer 2016. Available SSRN 2889436 2016. [CrossRef]

38. Ruipérez-Valiente, J.A.; Jenner, M.; Staubitz, T.; Li, X.; Rohloff, T.; Halawa, S.; Turro, C.; Cheng, Y.; Zhang, J.; Despujol, I.; et al. Macro MOOC learning analytics: Exploring trends across global and regional providers. In Proceedings of the Tenth International Conference on Learning Analytics \& Knowledge, Frankfurt am Main, Germany, 25-27 March 2020; pp. 518-523. 
39. Martinez, S. OCW (OpenCourseWare) and MOOC (open course Where?). In Proceedings of the OpenCourseWare Consortium Global, Ljubljana, Slovenia, 6 April 2014.

40. Fernndez, J.V.; Webster, S. From OCW to MOOC: Deployment of OERs in a massive open online course. The experience of Universidad Carlos III de Madrid (UC3M). Open Prax. 2014, 6, 145-158.

41. Höver, K.M.; Mühlhäuser, M. LOOCs_Linked Open Online Courses: A Vision. In Proceedings of the 2014 IEEE 14th International Conference on Advanced Learning Technologies, Athens, Greece, 7-10 July 2014; pp. 546-547.

42. Kagemann, S.; Bansal, S. MOOCLink: Building and utilizing linked data from massive open online courses. In Proceedings of the 2015 IEEE 9th International Conference on Semantic Computing (IEEE ICSC 2015), Anaheim, CA, USA, 7-9 Februry 2015; pp. 373-380.

43. Zotou, M.; Papantoniou, A.; Kremer, K.; Peristeras, V.; Tambouris, E. Implementing "rethinking education": Matching skills profiles with open courses through linked open data technologies. Bull. IEEE Tech. Comm. Learn. Technol. 2014, 16, 4 .

(C) 2020 by the authors. Licensee MDPI, Basel, Switzerland. This article is an open access article distributed under the terms and conditions of the Creative Commons Attribution (CC BY) license (http:/ / creativecommons.org/licenses/by/4.0/). 